\title{
Targeted delivery of albumin bound paclitaxel in the treatment of advanced breast cancer
}

This article was published in the following Dove Press journal:

OncoTargets and Therapy

6 July 2009

Number of times this article has been viewed

\author{
Francesco Di Costanzo' \\ Silvia Gasperoni' \\ Virginia Rotella' \\ Federica Di Costanzo \\ 'Struttura Complessa Oncologia \\ Medica, Azienda Ospedaliero \\ Universitaria Careggi, Florence; \\ ${ }^{2}$ Servizio di Oncologia: Ospedale S: \\ Maria della Stella, Orvieto, Italy
}

Correspondence: Francesco Di Costanzo Direttore S.C. di Oncologia Medica, Azienda Ospedaliero Universitaria Careggi, Florence, Italy Tel +39055 7949648

Fax +390557948394

Email oncmed02@aou-careggi.toscana.it; dicostanzofrancesco@tiscali.it

\begin{abstract}
Taxanes are chemotherapeutic agents with a large spectrum of antitumor activity when used as monotherapy or in combination regimens. Paclitaxel and docetaxel have poor solubility and require a complex solvent system for their commercial formulation, Cremophor $\mathrm{EL}^{\circledR}$ (CrEL) and Tween $80^{\circledR}$ respectively. Both these biological surfactants have recently been implicated as contributing not only to the hypersensitivity reactions, but also to the degree of peripheral neurotoxicity and myelosuppression, and may antagonize the cytotoxicity. Nab-paclitaxel, or nanoparticle albumin-bound paclitaxel (ABI-007; Abraxane ${ }^{\circledR}$ ), is a novel formulation of paclitaxel that does not employ the CrEL solvent system. Nab-paclitaxel demonstrates greater efficacy and a favorable safety profile compared with standard paclitaxel in patients with advanced disease (breast cancer, non-small cell lung cancer, melanoma, ovarian cancer). Clinical studies in breast cancer have shown that nab-paclitaxel is significantly more effective than standard paclitaxel in terms of overall objective response rate (ORR) and time to progression. Nab-paclitaxel in combination with gemcitabine, capecitabine or bevacizumab has been shown to be very active in patients with advanced breast cancer. An economic analysis showed that nab-paclitaxel would be an economically reasonable alternative to docetaxel or standard paclitaxel in metastatic breast cancer. Favorable tumor ORR and manageable toxicities have been reported for nab-paclitaxel as monotherapy or in combination treatment in advanced breast cancer.
\end{abstract}

Keywords: breast cancer, nab-paclitaxel, chemotherapy

\section{Introduction}

Taxanes have had an important influence on the treatment of a wide variety of cancers. ${ }^{1}$ The issue of efficacy has been evaluated with both paclitaxel and docetaxel. They are approved in many countries for the treatment of breast cancer, ovarian cancer, nonsmall cell lung cancer (NSCLC) and prostate cancer. These drugs can be given in a variety of schedules and can be combined with other drugs.

Paclitaxel has a poor solubility and requires a complex solvent system for its commercial formulation. Cremophor $\mathrm{EL}^{\circledR}(\mathrm{CrEL})$, a polyoxyethylated castor vehicle and dehydrated ethanol USP, was identified as the best option for the solvent system of paclitaxel. ${ }^{2}$

Docetaxel is a semisynthetic compound produced from 10-deacetylbaccatin-III, which is found in the needles of the European yew three, Taxus baccata. ${ }^{3}$ Docetaxel is more water soluble than paclitaxel, but requires equally complex solvent systems. ${ }^{4}$ For clinical use it is solubilized in a polyoxyethylated surfactant, polysorbate 80 (Tween $80^{\circledR}$ ).

The surfactants used in paclitaxel and docetaxel are biologically and pharmacologically active. A large number of biological effects have been reported in the literature 
on the use of taxanes, such as hypersensitivity reactions and peripheral neuropathies. Furthermore, several researchers have reported that these solvents modify the pharmacokinetic profiles of both drugs. Winner et al showed that a dose escalation of paclitaxel standard formulation increased toxicity, but without an increase of activity. ${ }^{5}$ Paclitaxel has pseudononlinear plasma pharmacokinetics that depend exclusively on CrEL. ${ }^{6}$ A reduction of clearance and a sequential high concentration of paclitaxel place the patients at risk for severe toxicity. The CrEL micelles may entrap other hydrophobic drugs (eg, doxorubicin) or inhibit drug uptake in the plasma (eg, cisplatin). ${ }^{7}$

CrEL, which is the vehicle for paclitaxel, has recently been implicated as contributing not only to the associated neuropathy, but also to the degree of myelosuppression, and may attenuate the effects of paclitaxel by causing micelle formation around the drug, which decreases the amount of the drug that can enter into the tumor cells. ${ }^{2,7,8-11}$

Polyethylated castor oil is believed to contribute to taxane-associated myelosuppression by inhibiting multi-drug resistance P-glycoprotein (MDR-P-GP) in hematopoietic progenitor cells. ${ }^{12}$ Polyethylated castor oil has a low distribution volume and remains within the vasculature compartment in continuous contact with bone marrow and may enhance myelosuppression, while having a lesser effect on MDR1 in tumor tissue.

Sensory and motor neuropathy are well-recognized toxicities of CrEL taxanes although whether CrEL is the sole cause of this toxicity remains unknown. ${ }^{13}$ Electrophysiologic studies in patients treated with paclitaxel have shown evidence of both axonal degeneration and demyelination. ${ }^{14}$ Administration of intravenous cyclosporine, which contains CrEL in its formulation, results in development of peripheral neuropathies in $25 \%$ of patients. ${ }^{15}$ The oral formulation of cyclosporine does not induce peripheral neurotoxicity, because the CrEL is not absorbed through the gastrointestinal tract. CrEL plasma concentrations achieved after administration of intravenous paclitaxel and cyclosporine have been shown to produce axonal swelling, vesicular degeneration and demyelinization in rat dorsal root ganglion neurons exposed to the formulation vehicle. ${ }^{16-18}$ Although sensory neuropathies have been associated with CrEL, the mechanism of taxane-induced neuropathy may be multifactorial.

A recent study has indicated that unsaturated fatty acids may cause neurotoxicity, possibly due to the appearance of peroxidation products, ${ }^{19}$ suggesting that the ethoxylated derivatives of castor oil probably account for most of the neuronal damage in addition to the presence of residual ethylene oxide residues.

Similarly, Tween 80, the vehicle for docetaxel, has also been implicated in some of the side effects. ${ }^{20}$

Docetaxel produces a mild and predominantly sensory neuropathy in a high proportion of treated patients. ${ }^{21}$ Treatment with steroids does not prevent docetaxel induced neuropathy. ${ }^{22}$ This effect depends upon the polyethylene substitutions produced by reaction of the polyol compound with ethylene oxide, even if etoposide that contains Tween 80 does not induce neuropathy. ${ }^{23,24}$

Moreover, when either of these drugs is administered, premedication with steroids is mandatory. This is a further disadvantage, because of patient convenience and because there are consequences after using steroids. Finally, there are hypersensitivity reactions associated with both drugs that can also be fatal. Consequently, those are some of the disadvantages associated with both drugs.

To reduce the potential disadvantages of paclitaxel and docetaxel, a number of novel taxanes are currently being developed. One of these new taxanes is nab-paclitaxel (Abraxane $^{\circledR}$; Abraxis Bioscience), or nanoparticle albuminbound paclitaxel.

\section{Pharmacokinetics and pharmacodynamics}

Nab-paclitaxel is prepared by high-pressure homogenization of paclitaxel in the presence of serum albumin, resulting in a nanoparticle colloidal suspension. ${ }^{25}$ These particles have an average size of approximately 130 to $150 \mathrm{~nm}$, approximately one-hundredth the size of a single red blood cell, and do not have the risk of capillary blockage concentration.

Sparreboon et al studied in a comparative preclinical and clinical study the pharmacokinetics of nab-paclitaxel and CrEL paclitaxel. ${ }^{26}$ Using a dose of $260 \mathrm{mg} / \mathrm{m}^{2}$ and $175 \mathrm{mg} / \mathrm{m}^{2}$ of nab-paclitaxel and CrEL paclitaxel, the half-life was 21.6 hours and 20.5 hours, respectively, while the areas under curve (AUC) were similar despite the different dose. Nab-paclitaxel had significantly higher plasma clearance and volume distribution. Disappearance from the blood is bi-phasic. The different pharmacokinetics of nab-paclitaxel reflects the entrapment absence of CrEL-paclitaxel in micelles, which are the principal carriers of paclitaxel in the systemic circulation.

When ABI-007 circulates, the particles are taken up through the endothelial wall, which is facilitated not only through leaky vessels but also through albondin (gp60), or an albumin receptor. Preclinical work has demonstrated that 
there is preferential uptake of nab-paclitaxel in the tumor tissue as opposed to paclitaxel. The albondin receptors transport albumin-bound drugs in exactly same way as does normal albumin. ${ }^{27}$ Albumin-bound macromolecules can leave the circulation through the leaky tumor microvasculature and accumulate in the interstitium because of the enhanced permeation and retention effects that are characteristic of neoplasia. In addition, albumin is actively transported across micro-vessel endothelial cells via unique receptor-mediated transport mechanism using gp60 receptor. When gp60 is activated, it interacts with caveolin-1 protein, leading to the formation of vesicles (caveolae) which then transport their cargo, albumin loaded with cytotoxic agent, across the endothelial cells and into the tumor interstitium where it is trapped.

Caveolin is the principal structural protein of caveolae, sphingolipid, and cholesterol-rich invaginations of the plasma membrane involved in vesicular trafficking and signal transduction. ${ }^{28}$ High expression of caveolin-1 has been associated with breast cancer and correlated with tumor aggressiveness and poor prognosis. ${ }^{29}$ The basal-like phenotype in sporadic and hereditary breast cancer has been associated with elevated expression of caveolin, leading Roy et al to theorize that nab-paclitaxel may be particularly active against breast cancer with basal-like phenotype. ${ }^{30}$ Polyethylated castor oil inhibits this transport mechanism. Many tumors secrete into the tumor's interstitium and onto the surface of the tumor cell, a protein known as secreted protein acidic and rich in cysteine (SPARC). As a result, the high affinity of SPARC for albumin is an albumin-cytotoxic uptake agent which serves to concentrate SPARC in the tumor. SPARC is overexpressed in breast cancer and has been implicated in tumor progression and angiogenesis. ${ }^{31} \mathrm{Nab}$-paclitaxel enhances tumor targeting through gp60 and caveolae-mediated endothelial transcytosis and the association with the albumin-binding protein SPARC in the tumor microenvironment.

Nab-paclitaxel is carried through this mechanism and can achieve enhanced intratumoral concentrations. Caveolin-2, SPARC, cortactin and dynamin 2 involved in the internalization of albumin may also be important in determining patient response to nab-paclitaxel. ${ }^{32,33}$

The overexpression of human epidermal growth factor receptor-2 (HER2) in breast cancer has been shown to correlate with resistance to paclitaxel. ${ }^{34}$ To evaluate the importance of HER2 and SPARC status in determining the relative efficacy of nab-paclitaxel compared with polysorbate-based docetaxel, nude mice bearing six different human tumor xenografts were treated with nab-paclitaxel and polysorbate-based docetaxel.
Nab-paclitaxel at submaximum-tolerated dosage was significantly more effective than polysorbate-based docetaxel at its maximum-tolerated dosage in HER2-negative tumors. The HER2-positive tumors had variable SPARC expression. In HER2-positive tumors, nab-paclitaxel was equal to or better than polysorbate-based docetaxel in tumors with medium to high SPARC levels, but not in tumors with low SPARC expression. These results demonstrated that the relative efficacy of nab-paclitaxel was significantly higher compared with polysorbate-based docetaxel in HER2-negative tumors and in HER2-positive tumors with high levels of SPARC. The nab-paclitaxel formulation provides several advantages over the classical formulation of paclitaxel: premedication is not required because the formulation does not include CrEL, the intravenous infusion time of nabpaclitaxel is shorter than CrEL-paclitaxel (30 minutes versus 3 hours), the set of infusion equipment does not require a particular type of plastic structure, and the volume for the reconstitution of nab-paclitaxel is reduced because it can be reconstituted in normal saline at concentration. ${ }^{35}$

Preclinical work has demonstrated that there is preferential uptake of nab-paclitaxel over paclitaxel in the tumor tissue.

Desai et al reported an increased activity in terms of efficacy and reduced toxicity of nab-paclitaxel in five animal models. ${ }^{36}$ They described the plasma pharmacokinetics and tumor tissue/red blood cell partitioning of radiolabeled paclitaxel from nab-paclitaxel and placlitaxel in athymic mice implanted with a human breast tumor cell line. Nabpaclitaxel partitioned rapidly into red blood cells after parenteral administration, and showed an enhanced biodistribution and prolonged half-life. The concentration of nab-paclitaxel in the tumor cells was 33\% higher than standard paclitaxel.

Studies in vitro suggest that one mechanism for resistance to chemotherapy is the increased expression of vascular endothelial growth factor A (VEGF-A) that is primarily responsible for the vascularization of solid tumors. ${ }^{37,38}$ Paclitaxel, docetaxel,${ }^{39}$ cisplatin, ${ }^{40}$ carboplatin, ${ }^{41}$ anthracyclines,,${ }^{42}$ fluorouracil ${ }^{43}$ can induce VEGF-A expression. Chemotherapy-induced VEGF-A production is possibly mediated by mitogen-activated protein kinase/extracellular regulated kinase pathway, nuclear factor $\kappa \mathrm{B}$, and phosphatidylinositol 3 kinase/AKT pathway. These pathways are typically activated in response to stress in both tumor and endothelial cells. Sweeny et al showed that VEGF-A protects endothelial cells from the cytotoxicity effect of docetaxel. ${ }^{44}$ VEGF-A significantly reduces nab-paclitaxel cytotoxicity and the combination of bevacizumab plus nab-paclitaxel abrogates the VEGF-A dependent protective effect on tumor cells. 
Volk et al demonstrated the effectiveness of this combination therapy in vitro against aggressive experimental metastatic breast cancer. ${ }^{45}$

A variety of other drugs are being investigated, including oral preparations of the taxanes as well as polyglutamated forms of the taxanes. Any one or all of these may have their own particular advantages and are still in development, so we do not yet know whether they will receive approval, or how they will compare with the currently approved taxanes, paclitaxel and docetaxel.

\section{Phase I studies}

Ibrahim et al reported a study of dose finding with nabpaclitaxel in 19 patients starting with a dose of 135 to $375 \mathrm{mg} / \mathrm{m}^{2}$ over 30 minutes every 21 days. ${ }^{25}$ The majority of patients were women with breast cancer. The maximum dose limiting toxicity was sensory neuropathy, stomatitis, and superficial keratopathy. All patients received a total of 96 cycles, and in 7 (7.3\%) cycles the neutrophil count nadir was $<500 / \mathrm{mm}^{3}$; six events occurred at the dose level above the maximum tolerated dose (MTD). The authors concluded that $300 \mathrm{mg} / \mathrm{m}^{2}$ is the dose to use for phase II trials. In this trial patients did not receive steroid and antihistamine premedication and no patients had hypersensitivity reaction.

A second trial evaluated the MTD using a weekly schedule of nab-paclitaxel. Dose ranged from 80 to $200 \mathrm{mg} / \mathrm{m}^{2}$ per week over 30 minutes for 3 of 4 weeks. ${ }^{46}$ The principal toxicity was neutropenia (grade 4) for heavily pre-treated patients and neuropathy (grade 3 ) for patients who had received less prior therapy. The authors suggest $150 \mathrm{mg} / \mathrm{m}^{2}$ week for treatment-naive patients and $100 \mathrm{mg} / \mathrm{m}^{2}$ week for heavily pre-treated patients.

In a phase I trial, nab-paclitaxel was administered by intra-arterial dose at 120 to $300 \mathrm{mg} / \mathrm{m}^{2}$ every 3 to 4 weeks with an acceptable toxicity. ${ }^{47,48}$

In a trial by Gardener et al patients with malignant solid tumors were randomized to receive the recommended singleagent dose of nab-paclitaxel $\left(260 \mathrm{mg} / \mathrm{m}^{2}\right)$ as a 30 -minute infusion or as solvent-based (sb)-paclitaxel $\left(175 \mathrm{mg} / \mathrm{m}^{2}\right)$ as a 3-hour infusion. After cycle 1, patients crossed over to the alternative treatment. ${ }^{49}$ Pharmacokinetic studies were carried out for the first cycle of sb-paclitaxel and the first two cycles of nab-paclitaxel. Seventeen patients were treated, 14 receiving at least one cycle each of nab-paclitaxel and sb-paclitaxel. No change in nab-paclitaxel pharmacokinetics was found between the first and second cycles $(p=0.95)$, suggesting limited intrasubject variability. Total drug exposure was comparable between the two formulations $(p=0.55)$ despite the dose difference. However, exposure to unbound paclitaxel was significantly higher after nabpaclitaxel administration, due to the increased free fraction $(0.063 \pm 0.021$ versus $0.024 \pm 0.009 ; p<0.001)$. This study shows that paclitaxel disposition is subject to considerable variability depending on the formulation used. Because systemic exposure to unbound paclitaxel is likely a driving force behind tumoral uptake, these findings explain, at least in part, previous observations that the administration of nabpaclitaxel is associated with augmented antitumor efficacy compared with sb-paclitaxel.

\section{Phase II trials}

Ibrahim et al treated 63 patients with breast cancer in a phase II trial with $300 \mathrm{mg} / \mathrm{m}^{2}$ of nab-paclitaxel every 3 weeks. ${ }^{50}$ Overall objective response rate (ORR) was $48 \%$ (95\% CI 35.3\%-60\%); the naive patients obtained a $64 \%$ (95 CI: $49 \%-79.2 \%$ ) of ORR and pre-treated $21 \%$ (95\% CI 7.1\%-42.1\%). Overall median time to progression (TTP) was 26.6 months and overall survival (OS) was 63.6 months. The median of cycles was six; $24 \%$ of patients had neutropenia grade $4,5 \%$ of whom had febrile neutropenia, and $11 \%$ of patients had neuropathy grade 3 .

A second phase II clinical trial investigated the activity of nab-paclitaxel $100 \mathrm{mg} / \mathrm{m}^{2}$ administered days 1,8 and 15 every 28 days in patients with taxane-refractory metastatic breast cancer. ${ }^{51} \mathrm{~A}$ total of 106 patients were enrolled and among the 66 evaluable patients, $13(20 \%)$ had a partial response (PR). Seven responding patients and 3 additional patients with stable disease (total of 10 patients, $15 \%$ ) continued abraxane for more than 24 weeks. Grade 4 toxicity was neutropenia, occurring in $5(8 \%)$ patients. Other toxicities (grade 2-3) included: nausea, infection, fatigue, vomiting, neuropathy, constipation, diarrhea, edema and mucositis.

Roy et al studied weekly nab-paclitaxel and gemcitabine combination in a phase II trial in patients with previously untreated metastatic breast cancer. ${ }^{30} \mathrm{Nab}$-paclitaxel $\left(125 \mathrm{mg} / \mathrm{m}^{2}\right)$ and gemcitabine $\left(1000 \mathrm{mg} / \mathrm{m}^{2}\right)$ were administered on days 1 and 8 every 21 days until disease progression. Of 50 treated patients, $40(80 \%)$ had visceral organ involvement and $30(60 \%)$ had 3 or more sites of metastases. Four $(8 \%)$ and 21 (42\%) patients had complete response and PR by Response Evaluation Criteria in Solid Tumors (RECIST) criteria. Median duration of response was 6.9 months (95\% CI 5.7, not reached), median progression-free survival (PFS) 7.9 months (95\% CI 5.4-10 months), and median OS was not reached. PFS and OS at 6 months were $60 \%(95 \%$ CI 48\%-76\%) and 92\% (95\% CI 85\%-100\%), respectively. 
Most frequent grade 3-4 toxicity included neutropenia (52\%), fatigue (28\%), anemia (14\%), dyspnea (14\%), and thrombocytopenia (12\%).

An unplanned subgroup analysis of triple-negative patients in this trial reported that 10 of $13(77 \%)$ of patients (95\% CI 46\%-95\%) had response compared with 16 of 36 other patients $(44 \%, 95 \%$ CI 28\%-62\%). These data suggest the possibility that basal-like breast cancer could be particularly responsive to the nab-paclitaxel regimen. In this trial, treatment was well tolerated. Neutropenia was the most common toxicity (grades 3-4 neutropenia: $43 \%$ and 12\%), only one patient developing febrile neutropenia.

Link et al reviewed, in a retrospective analysis, 40 women with breast cancer treated with a combination of nabpaclitaxel plus bevacizumab for a minimum of 2 courses. ${ }^{52}$ Of 33 women with measurable disease, 16 (48\%) had ORR to the nab-paclitaxel/bevacizumab regimen (3 complete response [CR] and $13 \mathrm{PRs}$ ). Median TTP for responders was 128 days and 135 days for the $15 \%$ of patients with stable disease (SD). Another 5 women had stable disease with a median duration of 135 days. Of 7 patients with bone-only disease, 2 had almost complete resolution of PET activity and 4 had SD (median, 148 days). Toxicity was acceptable, fatigue, neuropathy, pain, and hypertension being the most common complaints. In conclusion, this trial suggests a better outcome for patients treated with a weekly schedule (ORR + SD: $73.7 \%$ versus 50\%) than those on the 3-week treatment regimen. In Table 1 the ORR is reported based on tumor cell characteristics. ${ }^{52,53}$

An ongoing phase II trial, with nab-paclitaxel plus bevacizumab as first-line therapy for patients with breast cancer and Her-2 negative, showed no statistically or clinically significant differences in rates of grade 3-4 toxicities. This trial compared nab-paclitaxel $260 \mathrm{mg} / \mathrm{m}^{2}$ every 3 weeks to nab-paclitaxel $260 \mathrm{mg} / \mathrm{m}^{2}$ every 2 weeks plus filgrastim or nab-paclitaxel $130 \mathrm{mg} / \mathrm{m}^{2}$ weekly. ${ }^{54}$
Blum et al treated patients with metastatic breast cancer with weekly nab-paclitaxel. ${ }^{55}$ Women with metastatic breast cancer who were previously treated with taxanes were eligible for participation. Taxane failure was defined as metastatic disease progression during taxane therapy or relapse within 12 months of adjuvant taxane therapy. Primary objectives were ORR and toxicity. Women were treated with nab-paclitaxel $100 \mathrm{mg} / \mathrm{m}^{2}(\mathrm{n}=106)$ or $125 \mathrm{mg} / \mathrm{m}^{2}$ ( $n=75$ ) on days 1,8 , and 15 of a 28 -day cycle. ORR were $14 \%$ and $16 \%$ for the $100 \mathrm{mg} / \mathrm{m}^{2}$ and $125 \mathrm{mg} / \mathrm{m}^{2}$ cohorts, respectively; an additional $12 \%$ and $21 \%$ of patients, respectively, had stable disease for 16 weeks or more. Median PFS was 3 months at $100 \mathrm{mg} / \mathrm{m}^{2}$ and 3.5 months at $125 \mathrm{mg} / \mathrm{m}^{2}$; median survival times were 9.2 months and 9.1 months, respectively. Survival was similar for responding patients and those with SD. No severe hypersensitivity reactions were reported. Patients who developed treatment-limiting peripheral neuropathy typically could be restarted on a reduced dose of nab-paclitaxel after a 1- to 2-week delay. Grade 4 neutropenia occurred in $<5 \%$ of patients.

The combination of nab-paclitaxel and capecitabine was evaluated in patients with breast cancer. ${ }^{56}$ Preliminary data from an ongoing phase II study evaluated 50 treatment-naive patients with breast cancer using capecitabine $\left(825 \mathrm{mg} / \mathrm{m}^{2}\right.$ twice daily on days 1 to 14$)$ plus nab-paclitaxel $\left(125 \mathrm{mg} / \mathrm{m}^{2}\right.$ admistered on days 1 and 8) every 3 weeks. ORR was $47.5 \%$, complete response (CR) $8 \%$ in 38 evaluable patients, and SD in $39.4 \%$. Principal toxicity grade 3-4 was fatigue, hand-foot syndrome, febrile neutropenia or neutropenia alone.

\section{Phase III trials}

A randomized trial compared in 460 breast cancer patients a classical schedule of paclitaxel ( $175 \mathrm{mg} / \mathrm{m}^{2}$ in 3 hours) versus nab-paclitaxel $\left(260 \mathrm{mg} / \mathrm{m}^{2}\right.$ over 30 minutes $)$ every 3 weeks. ${ }^{57}$ In the arm with $\mathrm{CrEL}$ paclitaxel all patients received premedication with corticosteroid and antihistamines. Of all patients,

Table I Response rate and tumor cell characteristics of ABC treated with bevacizumab plus nab-paclitaxel${ }^{52,53}$

\begin{tabular}{|c|c|c|c|c|c|c|}
\hline & \multicolumn{6}{|l|}{ Response } \\
\hline & Total patients & CR (n) & ORR (\%) & SD (n) & CB (\%) & PD \\
\hline Er-pos or PgR-pos & 23 & 1 & $43.5 \%$ & 4 & $60.9 \%$ & 9 \\
\hline Er-neg or PgR-neg & 10 & 2 & $60 \%$ & I & $70 \%$ & 3 \\
\hline Her-2-neg & 21 & 2 & $47.6 \%$ & 1 & $52.4 \%$ & 10 \\
\hline Her-2-pos & 12 & I & $50 . \%$ & 4 & $83.3 \%$ & 2 \\
\hline Triple neg & 4 & I & $75 \%$ & 0 & $75 \%$ & I \\
\hline Total & 33 & 3 & $48.5 \%$ & 5 & $63.9 \%$ & 12 \\
\hline
\end{tabular}

Abbreviations: $C R$, complete response; ORR, overall response rate; PD, progressive disease; SD, stable disease; PgR, progesterone receptor; ER, estrogen receptor; CB, clinical benefit. 
$76 \%$ had more than three metastatic lesions and 79 patients had visceral disease. Of 460 patients, $86 \%$ were pre-treated with previous chemotherapy and $77 \%$ versus $78 \%$ of randomized patients had chemotherapy including anthracycline, in nab-paclitaxel and paclitaxel respectively. In the arm with nab-paclitaxel, ORR was significantly higher than with standard paclitaxel (33\% versus 19\%; $\mathrm{p}=0.001)$ and TTP was significantly longer (23.0 versus 16.9 weeks; hazard ratio $=0.75 ; \mathrm{p}=0.006)$, respectively. The ORR in the 97 treatment-naive patients was $42 \%$ in the nab-paclitaxel arm and $27 \%$ in the standard paclitaxel arm. When the patients were pre-treated with anthracyclines (adjuvant plus advanced), ORR was $34 \%$ and $18 \%$, respectively. In the nab-paclitaxel arm, patients received an average paclitaxel dose intensity $49 \%$ greater than patients in the standard paclitaxel arm. The incidence of hypersensitivity reactions (any grade) was low in both arms (nab-paclitaxel $<1 \%$ and CrELpaclitaxel 2\%). No patients in the experimental arm received premedication with steroids and antihistamines, but in $8 \%$ of patients steroids were administered for emesis, myalgia/arthralgia, or anorexia. The most frequent toxicities were alopecia, sensory neuropathy, fatigue, neutropenia, arthralgia/myalgia, nausea and diarrhea (Table 2).

Neutropenia grade 4 was significantly lower in the nab-paclitaxel arm (9\% versus $22 \%)$ with a higher mean neutrophil nadir. These data suggest that CrEL can contribute to this toxicity. Febrile neutropenia was uncommon $(<2 \%)$ in both study arms. Eight patients (3\%) in the nab-paclitaxel group and 14 patients $(6 \%)$ in the standard paclitaxel group received growth factor treatment for neutropenia during the study, without any toxic deaths. Peripheral neurotoxicity was more frequent in the experimental arm (10\% versus $2 \%$;

Table 2 Adverse events (all grades) reported in either group

\begin{tabular}{lllll}
\hline Adverse events & Nab-paclitaxel & & CrEL paclitaxel & p \\
\cline { 2 - 2 } \% of pts & & \% of pts & \\
Alopecia & 90 & 93 & $<0.00$ I \\
Sensory & 70 & 55 & \\
neuropathy & & 35 & \\
Fatigue & 45 & 50 & \\
Neutropenia & 30 & 29 & \\
Arthralgia & 30 & 28 & \\
Myalgia & 25 & 20 & \\
Nausea & 27 & 15 & \\
Diarrhea & 23 & 7 & \\
Hyperglycemia & 1 & 2 & \\
Hypersensitivity & $<1$ & & \\
reactions & & & & \\
\hline
\end{tabular}

$\mathrm{p}<0.001)$ because this group of patients received a higher dose of paclitaxel. No episodes of motor neuropathy or grade 4 sensory neuropathy were reported in either group. The researchers managed this toxicity by a reduction in dose and treatment interruption. In the arm with standard paclitaxel $7 \%$ of patients had higher serum glucose level than in the nab-paclitaxel arm $(1 \% ; p=0.003)$. The analyses of toxicity in patients over 65 years of age indicate that principal adverse events were notably lower in the nab-paclitaxel group, without any additional difference between older and younger patients (Table 3). Analyses of quality of life showed no difference despite the higher dose administered in the nabpaclitaxel group. This trial shows that with a new formulation of paclitaxel it is possible to deliver a higher dose of paclitaxel. ORR, TTP, and toxicity were significantly better with nab-paclitaxel than $\mathrm{CrEl}$ paclitaxel. These results were more evident in treatment-naive patients.

A randomized study evaluated the weekly schedule versus every-3-weeks schedule of nab-pacliatxel versus docetaxel in 302 patients with naive breast cancer. ${ }^{58}$ The primary end-point of this trial was ORR. Preliminary results (interim analysis) revealed that ORR in the every-3-weeks schedule of nab-paclitaxel and docetaxel were comparable (33 versus $36 \%$ ), while ORR in the weekly docetaxel schedule (100 and $150 \mathrm{mg} / \mathrm{m}^{2}$ ) was higher than with the every-3-weeks schedule (58\% versus 36\%, p $=0.004 ; 62 \%$ versus $36 \%, \mathrm{p}=0.016)$. There was no difference between the two schedules of nab-paclitaxel $(\mathrm{p}=0.424)$, while ORR in the weekly schedule was higher than with the 3-week schedule of nab-paclitaxel. Grade 4 neutropenia and febrile neutropenia were less frequent with nab-paclitaxel than with docetaxel. Peripheral neuropathy was $5 \%$ in the docetaxel arm and $14 \%$ in the nab-paclitaxel arm every 3 weeks, and $7 \%$ and $12 \%$, respectively, in the weekly schedule. This trial suggests that the weekly schedule of nab-paclitaxel is more effective than every 3 weeks in metastatic breast cancer (Table 4 and 5).

Table 3 Adverse events in patients $>65$ years old in the nab-paclitaxel group compared with the $\mathrm{CrEL}$-paclitaxel group

\begin{tabular}{llll}
\hline Adverse events & Nab-paclitaxel & & CrEL paclitaxel \\
\cline { 2 - 2 } & \% of pts & \% of pts \\
\hline Neutropenia & 23 & 59 \\
Leukopenia & 10 & 31 \\
Nausea & 20 & 38 \\
Hyperglycemya & 0 & 19 \\
Flushing & 0 & 16 \\
\hline
\end{tabular}


Table 4 Summary of phase II clinical studies of novel taxane formulations

\begin{tabular}{|c|c|c|c|c|c|c|c|c|}
\hline \multirow[t]{2}{*}{ Author } & \multirow[t]{2}{*}{ Regimen } & \multirow[t]{2}{*}{ No. patients } & \multicolumn{5}{|c|}{ Outcome } & \multirow{2}{*}{$\frac{\text { Toxicity }}{\text { Grade 3-4 (\%) }}$} \\
\hline & & & $\mathbf{R R} \%$ & TTP (mos) & PFS $\%$ & MS & OS & \\
\hline Ibrahim et $\mathrm{a}^{50}$ & Nab-paclitaxel300 mg/m² q3w & 63 & 48 & 26,6 & & & 63,6 & $\begin{array}{l}\text { Neutropenia g4 (24) } \\
\text { Neuropathy g3 (II) }\end{array}$ \\
\hline Blum et $\mathrm{a}^{51}$ & Nab-paclitaxel $100 \mathrm{mg} / \mathrm{m}^{2} \mathrm{w}$ & 66 & $20(\mathrm{RP})$ & & & & & $\begin{array}{l}\text { Neutropenia g4 (8) } \\
\text { Nausea g4 }(4,5) \\
\text { Infection g4 }(4,5)\end{array}$ \\
\hline Roy et a ${ }^{30}$ & $\begin{array}{l}\text { Nab-paclitaxel } 125 \mathrm{mg} / \mathrm{m}^{2} \mathrm{w}+ \\
\text { Gemcitabine } 1000 \mathrm{mg} / \mathrm{m}^{2} \mathrm{w}\end{array}$ & 50 & 50 & & 60 & & 92 & $\begin{array}{l}\text { Neutropenia g4 (12) } \\
\text { Neutropenia g3 (43) }\end{array}$ \\
\hline Link et $\mathrm{al}^{52}$ & Nab-paclitaxel plus Bevacizumab & 40 & 48,5 & 4,2 & & & & \\
\hline \multirow[t]{2}{*}{ Blum et a ${ }^{55}$} & Nab-paclitaxel $100 \mathrm{mg} / \mathrm{m}^{2} \mathrm{w}$ & $|8|$ & 14 & & 3 & 9,2 & & Neutropenia $g 4(<5)$ \\
\hline & Nab-paclitaxel $125 \mathrm{mg} / \mathrm{m}^{2} \mathrm{w}$ & & 16 & & 3,5 & 9,1 & & \\
\hline Schwartzberg et al ${ }^{56}$ & $\begin{array}{l}\text { Nab-paclitaxel } 125 \mathrm{mg} / \mathrm{m}^{2} \mathrm{w}+ \\
\text { Capecitabine } 825 \mathrm{mg} / \mathrm{m}^{2}\end{array}$ & 50 & 47,5 & & & & & $\begin{array}{l}\text { Neutropenia g4 (20) } \\
\text { Fatigue g4 (20) }\end{array}$ \\
\hline
\end{tabular}

Abbreviations: TTP, time to progression; MS, median survival; OS overall survival; PFS, progression free survival; RR, response rate; q3w, every 3 weeks; mos, months; w, week; MS, median survival.

For these drugs, the substantially lower neuropathy that improved rapidly (median 22 days), no need for premedication, and less myelosuppression should be highlighted. Then, of course, the next step is to see where these drugs fit into adjuvant therapy for the advanced stage setting.

An economic analysis comparing nab-paclitaxel and docetaxel, both as alternatives to paclitaxel in metastatic breast cancer, was conducted. ${ }^{59}$ The clinical and safety data were obtained from a meta-analysis of randomized trials comparing either nab-paclitaxel $\left(260 \mathrm{mg} / \mathrm{m}^{2}\right.$ every 3 weeks $)$ or docetaxel $\left(100 \mathrm{mg} / \mathrm{m}^{2}\right)$ every 3 weeks, with standard paclitaxel $\left(175 \mathrm{mg} / \mathrm{m}^{2}\right)$ every 3 weeks. Nab-paclitaxel had the lowest incidence of grade 3-4 toxicity. This translated to lower overall costs for managing the grade 3-4 events relative to both docetaxel and paclitaxel (US\$597 versus
US\$2626 versus US\$1227). Using the median number of cycles administered and the cost effect of grade III/IV toxicity, the overall cost for nab-paclitaxel would be US\$15,105 compared to US\$15,268 for docetaxel and US\$3557 for paclitaxel. When treatment preferences were assessed, 20 of $24(83.3 \%)$ respondents selected nab-paclitaxel as their preferred choice compared to only 4 who selected docetaxel. These corresponded to a gain of 0.203 and 0.016 quality adjusted life years (QALYs) for nab-paclitaxel and docetaxel, respectively. With these utility benefits, the incremental cost per QALY gained was more favorable for nabpaclitaxel than docetaxel (US\$56,800 versus US\$739,600). Nab-paclitaxel would be an economically reasonable alternative to docetaxel in metastatic breast cancer patients. The US Food and Drug administration approved nab-paclitaxel

Table 5 Summary of phase III clinical studies of novel taxane formulations

\begin{tabular}{|c|c|c|c|c|c|c|}
\hline \multirow[t]{2}{*}{ Author } & \multirow[t]{2}{*}{ Regimen } & \multirow[t]{2}{*}{ No. patients } & \multicolumn{3}{|c|}{ Outcome } & \multirow{2}{*}{$\frac{\text { Toxicity }}{\text { Grade 3-4 (\%) }}$} \\
\hline & & & $\mathbf{R R} \%$ & TTP (mos) & PFS (mos) & \\
\hline \multirow[t]{4}{*}{ Gradishar et al ${ }^{57}$} & Nab-paclitaxel $260 \mathrm{mg} / \mathrm{m}^{2} \mathrm{q} 3 \mathrm{w}$ & 229 & 33 & 23 & 25,7 & Neutropenia g4 (9) \\
\hline & vs & & & & & Neuropathy g3 (10) \\
\hline & Paclitaxel $175 \mathrm{mg} / \mathrm{m}^{2} \mathrm{q} 3 \mathrm{w}$ & 225 & 19 & 16,9 & 25,2 & Neutropenia g4 (22) \\
\hline & & & & & & Neuropathy g3 (2) \\
\hline \multirow{7}{*}{ Gradishar et al ${ }^{58}$} & Nab-paclitaxel 300 mg/m² q3w & 76 & 33 & & 10,6 & Neutropenia g4 (4) \\
\hline & vs & & & & & Neuropathy g3 (14) \\
\hline & Nab-paclitaxel $100 \mathrm{mg} / \mathrm{m}^{2} \mathrm{q} 3 / 4 \mathrm{w}$ & 76 & 58 & & 9,3 & Neutropenia g4 (3) \\
\hline & vs & & & & & Neuropathy g3 (7) \\
\hline & Nab-paclitaxel $150 \mathrm{mg} / \mathrm{m}^{2} \mathrm{q} 3 / 4 \mathrm{w}$ & 74 & 62 & & 9,2 & Neutropenia g4 (7) \\
\hline & vs & & & & & Neuropathy g3 (12) \\
\hline & Docetaxel $100 \mathrm{mg} / \mathrm{m}^{2} \mathrm{q} 3 / 4 \mathrm{w}$ & 74 & 36 & & 7,3 & Neutropenia g4 (74) \\
\hline
\end{tabular}

Abbreviations: TTP, time to progression; PFS, progression free survival; RR, response rate; $q 3 \mathrm{w}$, every 3 weeks; mos, months; w, week; MS, median survival; $\mathrm{q} 3 \mathrm{w}$, every 3 weeks; q3/4 w, every 3 or 4 weeks; mos, months; w, week. 
for the treatment of metastatic breast cancer after failure of combination chemotherapy or relapse after adjuvant therapy within 6 months.

\section{Neoadjuvant chemotherapy}

Preliminary studies have also evaluated nab-paclitaxel in neoadjuvant treatment of breast cancer. Sixty-six women with locally advanced breast cancer received neoadjuvant chemotherapy with 5-fluorouracil $\left(500 \mathrm{mg} / \mathrm{m}^{2}\right)$, epirubicin $\left(100 \mathrm{mg} / \mathrm{m}^{2}\right)$ plus cyclophosphamide $\left(500 \mathrm{mg} / \mathrm{m}^{2}\right)$ every 3 weeks and trastuzumab for HER-2 positive patients. ${ }^{60}$ All patients received 4 cycles of chemotherapy. CR was $32 \%$ (95\% CI, 21\%-45\%) with nab-paclitaxel in patients with HER-2 negative hormone receptor negative breast cancer, the CR was $29 \%$, while $59 \%$ in patients HER-2 positive hormone receptor negative breast cancer.

Somlo et al evaluated a neoadjuvant phase II trial in patients with stage 3-4 or inflammatory breast cancer. ${ }^{61}$ All patients received 6 cycles of docetaxel $\left(75 \mathrm{mg} / \mathrm{m}^{2}\right)$, doxorubicin $\left(50 \mathrm{mg} / \mathrm{m}^{2}\right)$, and cyclophosphamide $\left(500 \mathrm{mg} / \mathrm{m}^{2}\right)$ (TAC schedule), or doxorubicin $\left(600 \mathrm{mg} / \mathrm{m}^{2}\right)$ and cyclophosphamide $\left(600 \mathrm{mg} / \mathrm{m}^{2}\right)$ administered every 2 weeks for 4 cycles followed by carboplatin (AUC-2) and nab-paclitaxel $\left(100 \mathrm{mg} / \mathrm{m}^{2}\right.$ ) given every 4 weeks for 3 cycles (ACAC schedule).

Patients with HER-2 positive breast cancer received ACAC plus trastuzumab. In the TAC schedule, $7 \%$ of patients obtained CR, 5\% in the ACAC schedule and 40\% in the HER-2 positive patients (ACAC-T).

In the ACAC schedule, 7\% of 14 patients obtained pathological $\mathrm{CR}$ and $23 \%$ minimal residual cancer burden (RCB), as in the TAC schedule arm, compared with $40 \%$ (CR) and $0 \%(\mathrm{RCB})$ of 10 patients treated with ACAC-T and $\mathrm{TAC}$, respectively.

Principal toxicities included neuropathy, neutropenia, febrile neutropenia, trombocitopenia, anemia, fatigue, gastrointestinal toxicities, while the highest rate of grade 4 neutropenia occurred in the TAC schedule.

Daniel et al treated 72 women with breast cancer with gemcitabine $\left(2000 \mathrm{mg} / \mathrm{m}^{2}\right)$, epirubicin $\left(50 \mathrm{mg} / \mathrm{m}^{2}\right)$ and nab-paclitaxel $\left(175 \mathrm{mg} / \mathrm{m}^{2}\right)$ every 2 weeks for 6 cycles as neoadjuvant treatment. ${ }^{62}$ Of 35 patients evaluable for response, $20 \%$ had pathological CR and 74\% PR, while 6\% had SD.

Neutropenia grade 3-4 was $8 \%$, thrombocytopenia $6 \%$, without febrile neutropenia or grade 3-4 neuropathy. Trials with the combination including nab-paclitaxel as adjuvant therapy for breast cancer are ongoing and preliminary results are promising.

\section{Conclusions}

Clinical studies have shown that nab-paclitaxel has substantial activity and manageable toxicity as chemotherapy for breast cancer, and the outcome is better than with paclitaxel formulated with CrEL, with almost double the ORR, increased TTP and increased survival in second-line patients. The nab formulation is associated with decreased neutropenia and rapid improvement of peripheral neuropathy compared with CrEL-paclitaxel. For these reasons, nab-paclitaxel can be administered by using higher doses of paclitaxel than those achievable with CrEL-paclitaxel, with shorter infusion duration and without a mandatory premedication with corticosteroids and antihistamines to reduce the risk of solvent-mediated hypersensitivity reactions. Nab technology has increased the therapeutic index of paclitaxel in breast cancer compared with the conventional solvent-based formulations. Further randomized trials in advanced and adjuvant treatment of breast cancer using nab-paclitaxel in combination with other drugs are needed.

\section{Disclosures}

The authors declare no conflicts of interest.

\section{References}

1. Schiff PB, Fant J, Horowitz SB. Promotion of microtubule assembly in vitro by taxol. Nature. 1979;227:665-667.

2. Ten Tije AJ, Verweij J, Loos WJ, et al. Pharmacological effects of formulation vehicles: implications for cancer chemotherapy. Clin Pharmacokinet. 2003;42:665-685.

3. Gelmon K. The taxoids: paclitaxel and docetaxel. Lancet. 1994;344: 1267-1272.

4. Boehnke Michaud L, Valero V, Hortobagyi GN. Risks and benefits of taxanes in breast and ovarian cancer. Drug Safety. 2000;23:401-428.

5. Winer EP, Berry DA, Woolf S, Duggan D, Kornblith A, Harris LN. Failure of higher dose paclitaxel to improve outcome in patients with metastatic breast cancer: Cancer and Leukemia GroupB trial 9342. J Clin Oncol. 2004;22:2061-2068.

6. Sparreboom A, van Tellingen O, Nooijen WJ, et al. Nonlinear pharmacokinetics of paclitaxel in mice results from the pharmaceutical vehicle Cremophor EL. Cancer Res. 1996;56:2112-2115.

7. van Zuylen L, Verweij J, Sparreboom A. Role of formulation vehicles in taxane pharmacology. Invest New Drugs. 2001;19:125-141.

8. Gelderblom H, Verweij J, Nooter K, et al. Cremophor EL: The drawbacks and advantages of vehicle selection for drug formulation. Eur J Cancer. 2001;37:1590-1598.

9. Jain RK: Barriers to drug delivery in solid tumors. Sci Am. 1994;271: $58-65$.

10. Knemeyer I, Wientjes MG, Au JLS. Cremophor reduces paclitaxel penetration into bladder wall during intravesical treatment. Cancer Chemother Pharmacol. 1999;44:241-248.

11. Kumar GN, Walle UK, Bhalla KN, et al. Binding of Taxol to human plasma, albumin and alpha1-acid glycoprotein. Res Commun Chem Pathol Pharmacol. 1993;80:337-344.

12. Sparreboom A, Verweij J, van der Burg ME, Loos WJ, Brouwer E, Viganò L. Disposition of Cremophor EL in humans limits the potential for modulation of the multidrug resistance phenotype in vivo. Clin Cancer Res. 1998;4:1937-1942. 
13. Postma TJ, Vermorken JB, Liefting AJM, et al. Paclitaxel-induced neuropathy. Ann Oncol. 1995;6:489-494.

14. Onetto N, Canetta R, Winograd B, et al. Overview of taxol safety. J Natl Cancer Inst. 1993;15:131-139.

15. de Groen PC, Aksamit AJ, Rakela J, et al. Central nervous system toxicity after liver transplantation. The role of cyclosporine and cholesterol. N Engl J Med. 1987;317:861-866.

16. Windebank AJ, Blexrud MD, de Groen PC. Potential neurotoxicity of the solvent vehicle for cyclosporine. J Pharmacol Exp Ther. 1994; 268:1051-1056.

17. Aventis Pharmaceuticals Inc. Taxotere (docetaxel): prescribing information. Bridgewater, NJ: Aventis Pharmaceuticals; 2002.

18. Boer HM, Moorer-van Delft CM, Muller LJ, et al. Ultrastructural neuropathologic effects of Taxol on neurons of the fresh-water snail Lymnaea stagnalis. J Neurooncol. 1995;25:49-57.

19. Brat DJ, Windebank AJ, Brimijoin S. Emulsifier for intravenous cyclosporine inhibits neurite outgrowth, causes deficits in rapid axonal transport and leads to structural abnormalities in differentiating N1E.115 neuroblastoma. J Pharmacol Exp Ther. 1992;261: 803-810.

20. Crown J, O'Leary M: The taxanes: an update. Lancet. 2000;355(9210): 1176-1178.

21. New PZ, Jackson CE, Rinaldi D, et al. Peripheral neuropathy secondary to docetaxel (Taxotere). Neurology. 1996;46:108-111.

22. Pronk LC, Hikens PH, van den Bent MJ, et al. Corticosteroid co-medication does not reduce the incidence and severity of neurotoxicity induced by docetaxel. Anticancer Drugs. 1998;9: 759-764.

23. Verweij J, Clavel M, Chevalier B. Paclitaxel (Taxol) and docetaxel (Taxotere): not simply two of kind. Ann Oncol. 1994;5:495-505.

24. Freilich RJ, Balmaceda C, Seidman AD, et al. Motor neuropathy due to docetaxel and paclitaxel. Neurology. 1996;47:115-118.

25. Ibrahim NK, Desai N, Legha S, Soon-Shiong P, Theriault RL, Rivera E. Phase I and pharmacokinetic study of ABI-007, a Cremophor-free, protein-stabilized, nanoparticle formulation of paclitaxel. Clin Cancer Res. 2002;8:1038-1044.

26. Sparreboom A, van Zuylen L, Brouwer E, Loos WJ, de Bruijn P, Gelderblom H. Cremophor EL-mediated alteration of paclitaxel distribution in human blood: clinical pharmacokinetic implications. Cancer Res. 1999;59(7):1454-1457.

27. Schnitzer JE, Oh P. Antibodies to SPARC inhibit albumin binding to SPARC, gp60, and microvascular endothelium. Am J Physiol. 1992;263(6 Pt 2):H1872-H1879.

28. Bouras T, Lisanti MP, Pestelli RG. Caveolin-1 in breast cancer. Cancer Biol Ther. 2004;3(10):931-941.

29. Yang G, Truong LD, Timme TL, et al. Elevated expression of caveolin is associated with prostate and breast cancer. Clin Cancer Res. 1998;4(8):1873-1880.

30. Roy V, Laplant BR, Gross GG, et al. for the North Central Cancer Treatment Group. Phase II trial of weekly nab (nanoparticle albuminbound)-paclitaxel (nab-paclitaxel) (Abraxane) in combination with gemcitabine in patients with metastatic breast cancer (NO531). Ann Oncol. 2009;20:449-453.

31. Watkins G, Douglas-Jones A, Bryce R, et al. Increased levels of SPARC (osteonectin) in human breast cancer tissues and its association with clinical outcomes. Prostaglandins Leukot Essent Fatty Acids. 2005;72(4):267-272.

32. Parton RG, Simons K. The multiple faces of caveolae. Nat Rev Mol Cell Biol. 2007;8(3):185-194.

33. Pelkmans L, Puntener D, Helenius A. Local actin polymerization ad dynamin recruitment in SV40 induced internalization of caveolae. Science. 2002;296(5567):535-539.

34. Desai NP, Trieu V, Hwang LY, Wu R, Soon-Shiong P, Gradishar WJ. Improved effectiveness of nanoparticle albumin-bound (nab) paclitaxel versus plysorbate-based docetaxel in multiple xenografts as a function of HER2 and SPARC status. Anticancer Drugs. 2008;19(9): 899-909.
35. Green MR, Manikhas GM, Orlov S, Afanasyev B, Makhson AM, Bhar P, et al. Abraxane, a novel Cremophor-free, albumin-bound particle form of paclitaxel for the treatment of advanced non-small-lung cancer. Ann Oncol. 2006;17(8):1263-1268.

36. Desai N, Trieu V, Yao Z, et al. Increased antitumor activity, intratumor paclitaxel concentrations, and endothelial cell transport of cremophor-free, albumin-bound paclitaxel, ABI-007, compared with cremophor-based paclitaxel. Clin Cancer Res. 2006;12(4):1317-1324.

37. Ferrara N. VEGF as a therapeutic target in cancer. Oncology. 2005; 69(Suppl 3):11-16.

38. Ferrara N, Hillan KJ, Novotny W. Bevacizumab (Avastin), a humanized anti-VEGF monoclonal antibody for cancer therapy. Biochem Biophys Res Commun. 2005;333: 328-335.

39. McDaid HM, Lopez-Barcons L, Grossman A, Lia M, Keller S, PérezSoler R, et al. Enhancement of the therapeutic efficacy of taxol by the mitogen-activated protein kinase kinase inhibitor CI-1040 in nude mice bearing human heterotransplants. Cancer Res. 2005;65:2854-2860.

40. Miyahara Y, Yoshida S, Motoyama S, Tateiwa Y, Hamana S, Maruo T. Effect of cis-diammine dichloroplatinum on vascular endothelial growth factor expression in uterine cervical carcinoma. Eur J Gynaecol Oncol. 2004;25:33-39.

41. Wild R, Dings RP, Subramanian I, et al. Carboplatin selectively induces the VEGF stress response in endothelial cells: potentiation of antitumor activity by combination treatment with antibody to VEGF. Int J Cancer. 2004;110:343-351.

42. Mills PJ, Parker B, Jones V, Adler KA, Perez CJ, Johnson S, et al. The effects of standard anthracycline-based chemotherapy on soluble ICAM-1 and vascular endothelial growth factor levels in breast cancer. Clin Cancer Res. 2004;10:4998-5003.

43. Riedel F, Gotte K, Goessler U, Sadick H, et al. Targeting chemotherapyinduced VEGF up-regulation by VEGF antisense oligonucleotides in HNSCC cell lines. Anticancer Res. 2004;24:2179-2183.

44. Sweeney CJ, Miller KD, Sissons SE, Nozaki S, Heilman DK, Shen J. The antiangiogenic property of docetaxel is synergistic with a recombinant humanized monoclonal antibody against vascular endothelial growth factor or 2-methoxyestradiol but antagonized by endothelial growth factors. Cancer Res. 2001;61:3369-3372.

45. Volk LD, Flister MJ, Bivens CM, Stutzman A, Desai N, Trieu V. Human breast cancer is significantly enhanced by concurrent anti-vascular endothelial growth factor A therapy. Neoplasia. 2008;10:613-623.

46. Nyman DW, Campbell KJ, Hersh E, et al. Phase I and pharmacokinetics trial of ABI-007, a novel nanoparticle formulation of paclitaxel in patients with advanced nonhematologic malignancies. J Clin Oncol. 2005;23:7785-7793.

47. Damascelli B, Cantu G, Mattavelli F, et al. Intraarterial chemotherapy with polyoxyethilated castor oil free paclitaxel, incorporated in albumin nanoparticles (ABI-007). Cancer. 2001;92:2592-2602.

48. Damascelli B, Patelli G, Lanocita R, et al. A novel intraarterial chemotherapy using paclitaxel in albumin nanoparticles to treat advanced squamous cell carcinoma of the tongue:preliminary findings. $\mathrm{Am} \mathrm{J}$ Roentgenol. 2003;181: 253-260.

49. Gardner ER, Dahut WL, Scripture CD, Jones J, Aragon-Ching JB, Desai N. Randomized crossover pharmacokinetic study of solventbased paclitaxel and nab paclitaxel. Clin Cancer Res. 2008;14(13): 4200-4205.

50. Ibrahim NK, Samuels B, Page R, Doval D, Patel KM, Rao SC. Multicenter Phase II trial of ABI-007, an albumin-bound paclitaxel, in women with metastatic breast cancer. J Clin Oncol. 2005;23(25):6019-6026.

51. Blum JL, Savin MA, Edelman G, Pippen JE, Robert N, Sandbach J. Long term disease control in taxane-refractory metastatic breast cancer treated with nab paclitaxel [abstract]. J Clin Oncol. 2004;22(14 Suppl): Abstract 543.

52. Link JS, Waisman JR, Nguyen B, et al. Bevacizumab and albuminebound paclitaxel treatment in metastatic breast cancer. Clin Breast Cancer. 2007;(10):779-783. 
53. Gradishar W, Cortes J. Clinical efficacy and emerging therapeutic utilization of novel taxanes. EJC Supplements. 2008;10(6):12-21.

54. Conlin AK, Seidman AD, Moynahan, et al. Randomized phase II trial of three dosing schedules of nanoparticle albumin-bound paclitaxel with bevacizumab as first-line therapy for HER2 negative metastatic breast cancer: An initial interim safety report [abstract]. J Clin Oncol. 2007;25(18S part I):1104.

55. Blum JL, Savin MA, Edelman G, Pippen JE, Robert NJ, Geister BV. Phase II study of weekly albumin - bound paclitaxel for patients with metastatic breast cancer heavily pretreated with taxanes. Clin Breast Cancer. 2007;(11):580-586.

56. Schwartzberg LS, Arena F, Mintzer D, et al. Phase II trial of nanoparticle albumin-bound paclitaxel $(\mathrm{ABX})+$ capecitabine (XEL) in first line treatment of metastatic breast cancer (MBC):interim results [abstract]. Breast Cancer Res Treat. 2006;100(Suppl 1):1096.

57. Gradishar WJ, Tjulandin S, Davidson N, Shaw H, Desai N, Bhar P. Phase III trial of nanoparticle albumin-bound paclitaxel compared with polyethylated castor oil-based paclitaxel in women with breast cancer. J Clin Oncol. 2005;23(31):7768-7771.

58. Gradishar W, Krasnojon D, Cheporov S. Manikhas G, Clawson A, Hawkins MJ. Randomized comparison of weekly or every-3-week (q3w) nab-paclitaxel compared to $\mathrm{q} 3 \mathrm{w}$ docetaxel as first-line therapy in patients (pts) with metastatic breast cancer (MBC). J Clin Oncol. 2007;25(Suppl):18S.
59. Dranitsaris G, Cottrel W, Spirovski B, et al. Economic analysis of albumin-bound paclitaxel for the treatment of metastatic breast cancer. J Oncol Pharm Pract. 2008; Nov 26 (Epub ahead of print).

60. Robidoux A, Buyse M, Buzdar A, et al. Neoadjuvant chemotherapy with sequential weekly nanoparticle albumin-bound paclitaxel (ABI-007, Abraxane) followed by 5 -fluorouracil, epirubicin and cyclophosphamide (FEC) in locally advanced breast cancer (LABC): a phase II trial of the NSABP Foundation research programs (FRP) [abstract]. Breast Cancer Res Treat. 2006;100 (Supp1 1):3068 (abstract).

61. Somlo G, Paz B, Shen J, et al. A randomized phase II neoadjuvant trial in patients with stage II-III and inflammatory breast cancer. Breast Cancer Res Treat. 2007;106:5073.

62. Daniel BR, Doss H, Gian V, et al. Biweekly neoadjuvant gemcitabine, epirubicin, and nano-particle albumin bound (nab) paclitaxel (GEA) with tumor SPARC analysis correlated with pathological responses: Results of a multicenter phase II trial. J Clin Oncol. 2007; 25(18S part I):11060.
OncoTargets and Therapy

\section{Publish your work in this journal}

OncoTargets and Therapy is an international, peer-reviewed, open access journal focusing on the pathological basis of all cancers, potential targets for therapy and treatment protocols employed to improve the management of cancer patients. The journal also focuses on the impact of management programs and new therapeutic agents and protocols on

\section{Dovepress}

patient perspectives such as quality of life, adherence and satisfaction The manuscript management system is completely online and includes a very quick and fair peer-review system, which is all easy to use. Visit http://www.dovepress.com/testimonials.php to read real quotes from published authors. 